\title{
Entrepreneurship
}

Jul a Dez $2020-$ v.4 - n.2

ISSN: 2595-4318

This article is also available online at: www.sustenere.co

\section{Responsabilidade social empresarial: uma revisão de literatura (2018-2019)}

A Responsabilidade Social Empresarial abrange ações desenvolvidas pelas empresas que tem a visão de contribuir para uma sociedade mais justa e igualitária, e também pensado na preservação do meio ambiente e na sustentabilidade. O presente estudo tem como objetivo apresentar uma revisão da literatura sobre Responsabilidade Social Empresarial entre os anos de 2018 e 2019 indexados na Scientific Electronic Library Online-SciELO. A metodologia utilizada para realizar o estudo possui uma abordagem quantitativa exploratória. No que tange o tipo de investigação, o estudo é classificado como uma revisão da literatura. A base de dados utilizada para a revisão foi a Scientific Electronic Library Online-SciELO, tendo como descritor o termo: Responsabilidade Social Empresarial. Considera-se que as empresas através da Responsabilidade Social compreendem que se há o desenvolvimento regional e local de modo sustentável, há uma maior chance de crescimento empresarial, uma vez que as mudanças nas realidades individuais e coletivas adentram nas organização na forma de colaboradores mais motivados, com melhor saúde e educação.

Palavras-chave: Responsabilidade Social Empresarial; Sociedade; Sustentabilidade.

\section{Corporate social responsibility: a literature review (2018-2019)}

Corporate Social Responsibility encompasses actions developed by companies that have the vision to contribute to a fairer and more egalitarian society, as well as the preservation of the environment and sustainability. This study aims to present a review of the literature on Corporate Social Responsibility between 2018 and 2019 indexed in the Scientific Electronic Library Online-SciELO. The methodology used to conduct the study has an exploratory quantitative approach. Regarding the type of investigation, the study is classified as a literature review. The database used for the review was the Scientific Electronic Library Online-SciELO, having as descriptor the term: Corporate Social Responsibility. Companies through Social Responsibility are considered to understand that if sustainable regional and local development is present, there is a greater chance of business growth, as changes in individual and collective realities enter organizations in the form of more motivated employees, with better health and education.

Keywords: Corporate Social Responsibility; Society; Sustainability.

Topic: Planejamento, Estratégia e Competitividade

Reviewed anonymously in the process of blind peer
Received: 18/03/2020

Approved: 08/04/2020
Mikaely Sombra da Silva ib

Centro Universitário Vale do Salgado, Brasil

http://lattes.cnpq.br/6483077323588127

mikaelysbr@gmail.com

Antoniel dos Santos Gomes Filho (iD

Centro Universitário Vale do Salgado, Brasil

http://lattes.cnpq.br/9563145614494252

http://orcid.org/0000-0003-2230-4315

antonielsantos@fvs.edu.br
DOI: 10.6008/CBPC2595-4318.2020.002.0004
Referencing this:

SILVA, M. S.; GOMES FILHO, A. S.. Responsabilidade social empresarial: uma revisão de literatura (2018-2019). Entrepreneurship, v.4, n.2, p.37-42, 2020. DOI: http://doi.org/10.6008/CBPC25954318.2020.002.0004 


\section{INTRODUÇÃO}

Entende-se como responsabilidade social ações desenvolvidas pelas empresas que tem a visão de contribuir para uma sociedade mais justa e igualitária, e também pensado na preservação do meio ambiente e na sustentabilidade. São atos e ações onde as organizações direcionam suas atividades para o bem-estar social, conduzindo seus negócios de forma que abarque o interesse coletivo e não visando somente a lucratividade, haja vista que o todo seja priorizado. A responsabilidade social está ligada ao conceito de sustentabilidade, onde se trabalha três eixos: cultural, social e ambiental.

As empresas que estão inseridas em contextos socialmente responsáveis têm ações voltadas para projetos que envolvem tanto os colaboradores internos, como a comunidade em que está inserida. Na atualidade é notório o trabalho que as empresas vêm fazendo através de Projetos Sociais, o que não se confunde com assistencialismo, e sim com a compreensão do comprometimento das empresas com sua função na sociedade. Ações voltadas às áreas de saúde, assistência social, cultura, fomento à educação e a moradia, dentre outros, são exemplos de responsabilidade social.

Vale ressaltar que não se trata de meras atitudes com vistas a prevenir sanções e a reduzir seus impostos, tampouco para atender as legislações vigentes, que são pontos importantes. Na verdade, os ganhos da empresa socialmente responsável são inestimáveis e alcançados ao longo do tempo. A responsabilidade social estimula as empresas juntamente com toda comunidade local e regional á se fazerem presentes no desenvolvimento de suas ações e interesses que busquem o desenvolvimento individual e coletivo. Diante desse quadro, observa-se que a Responsabilidade Social Empresarial vem sendo alvo de muitos estudos acadêmicos nos últimos anos. Assim, livros, artigos científicos, relatórios técnicos, etc. podem ser visualizados em bases de dados científicas, demostrando que o assunto é alvo de pesquisas empíricas e teóricas. Desse modo, tem-se a seguinte indagação: o que as publicações científicas na modalidade artigo têm discutido sobre responsabilidade social empresarial?.

O presente estudo tem como objetivo apresentar uma revisão da literatura sobre Responsabilidade Social Empresarial entre os anos de 2018 e 2019 indexados na ScientificElectronic Library Online-SciELO.

A metodologia utilizada para realizar o estudo possui uma abordagem quantitativa (FLICK, 2009). Haja vista que os objetivos traçados durante a pesquisa, os mesmos possuem um caráter exploratório (GIL, 2009). No que tange o tipo de investigação, o estudo é classificado como uma revisão da literatura (MARCONI et al., 2017). A base de dados utilizada para a revisão foi a Scientific Electronic Library Online-SciELO, tendo como descritor o termo: Responsabilidade Social Empresarial. Foram utilizados como filtros de pesquisa: Coleções Brasil; Idioma Português; Anos de publicação, 2018 e 2019; Tipo de Literatura, Artigos. Diante dos filtros inseridos obteve-se o seguinte resultado: pesquisa inicial sem filtros: 203 artigos na base; com inserção dos filtros: 4 artigos na base. Destaca-se que os 4 artigos foram selecionados para o estudo, pois não houve duplicação, e todos atendiam ao foco deste estudo.

O presente trabalho tem como justificativa salientar a importância da prática da responsabilidade social como um alicerce para a gestão organizacional, já que vem compelir as empresas ao desenvolvimento 
sustentável, ao compromisso com a sociedade e a transparência com o público de interesse, ou seja, tem como ponto primordial a busca da qualidade nas dimensões econômicas, sociais e ambientais, agregando assim credibilidade para a imagem da empresa.

\section{METODOLOGIA}

A responsabilidade social surge de um acordo da empresa com a sociedade, sua presença no mercado vai mais além do que gerar empregos, impostos e lucros. A estabilização da organização dentro do ecossistema social estar sujeito primeiramente de um desempenho responsável e ética (REBAÇA et al., 2001; SERPA et al., 2007).

Segundo Simões (2008) a Responsabilidade Social tem como principal foco aprimorar a qualidade de vida da sociedade como um todo. Ser socialmente responsável vai muito além de gerar empregos, impostos e lucros, vai mostra o desempenho da organização dentro do meio social estar sujeito basicamente na performance responsável e ética em presença da sociedade, em acordo com da forma do desenvolvimento ecológico, econômico e também com social.

De acordo com Reis (2007) a responsabilidade social no Brasil, começou a ser debatida na década de 60, com a surgimento da Associação dos Dirigentes Cristãos de Empresas (ADCE), o principal começo desse instituto fundar-se na aceitação, por seus componentes, de que a companhia, além de fabricar bens e serviços tem a função social que se alcança em nome dos colaboradores e do bem-estar da sociedade.

De acordo com Rico (2004) a responsabilidade social corporativa empresarial aparece com a transformação de importâncias indicados pela sociedade pós-industrial: a valorização das pessoas, o respeito ao ecossistema, a procura de uma sociedade mais justa e uma empresa de com vários objetivos. Os novos valores pós-econômicos são além disso abertura na crescente insistência pública de que as alianças se atentem com a execução para a sociedade como um todo.

\section{DISCUSSÃO TEÓRICA}

\section{Responsabilidade social empresarial: o que aponta a literatura}

Paiva et al. (2019) no estudo intitulado: Gestão socioambiental em micro e pequenas indústrias de Pau dos Ferros-RN, apontam que ao longo de gerações, atividades antrópicas têm desencadeado uma séria de desequilíbrios ambientais, ocasionando mudanças na estrutura e composição do solo, na qualidade da água e do ar, bem como em diversos outros fatores envoltos ao meio ambiente. Diante destas constatações, a busca pelo desenvolvimento sustentável, por parte da indústria e toda a sua cadeira produtiva, tem se tornado imprescindível para que possamos aliar o crescimento industrial ao consumo adequado dos recursos naturais, partindo da premissa da responsabilidade empresarial socioambiental. Dentro desse viés, levando em consideração crescente desenvolvimento industrial, populacional e educacional da cidade de Pau dos Ferros/RN, objetivou-se, a partir da realização deste trabalho, analisar a percepção de gestores de micro e pequenas indústrias da referida cidade acerca de práticas socioambientais. 
A metodologia experimental deste estudo deu-se por meio de pesquisa qualitativa descritiva em campo, em que, através de entrevistas e observação direta informal, realizou-se a coleta de dados em Micro e Pequenas Indústrias na cidade de Pau dos Ferros, localizada na Mesorregião Oeste, do Estado do Rio Grande do Norte. Por meio da obtenção e análise dos dados, constatou-se que os gestores, em sua totalidade, demonstram conhecimento no que se refere a importância do meio ambiente. Parte majoritária destes gestores desenvolvem ações de cunho ambiental em suas empresas, principalmente àquelas com o objetivo de economia de água e energia, bem como o reaproveitamento de materiais, seja por motivação econômica (redução de custos) ou adequação a práticas sustentáveis. Ainda assim, evidenciam que estas ações necessitam de investimentos e incentivos por parte do governo para que sejam implantadas e desenvolvidas. Diante do exposto, pode-se inferir que as organizações empresariais têm buscado adota práticas sustentáveis na realização de suas atividades, em detrimento aos problemas socioambientais, no intuito de contribuir para a formação de uma sociedade mais justa e consciente de seus atos (PAIVA et al., 2019).

Andrade et al. (2018) no estudo intitulado: Análise comparativa das normas de gestão de responsabilidade social e sua abrangência; destacam que a responsabilidade social, inicialmente restrita às atividades filantrópicas, por meio dos seus modelos de gestão, almeja a implantação de técnicas que proporcionem melhorias e resultados significativos dentro das organizações, tanto no que se refere ao dimensionamento da gestão da responsabilidade social, como no que tange a gestão de aspectos e impactos, sejam de eles positivos ou negativos. Assim, este estudo tem como objetivo o levantamento e avaliação dos principais modelos e padrões normativos para a gestão da responsabilidade social existente em nível mundial, além de analisar as normas de gestão de responsabilidade social de forma comparativa, quanto a suas estruturas e escopo, e apresentar a contribuição delas para a qualidade de vida no trabalho e os fatores econômicos relacionados. A metodologia empregada no desenvolvimento deste estudo, deu-se por meio da pesquisa bibliográfica aos conceitos e origem da responsabilidade social, bem como às normas existentes, suas origens e seus principais objetivos.

A partir dos dados encontrados na literatura, entende-se que as normas podem ser classificadas de acordo com seu objetivo, existindo normas desenvolvidas para a certificação e normas para a definição de padrões de processo. Dentre as principais normas e modelos de gestão, disponíveis e vigorantes, destacamse: Norma Social Accountability SA 8000; Norma ISO 26.000; Modelo Sedex MembersEthical Trade Audit; Código de Conduta BSCl; Norma Assurance Standard AA1000; Norma IQNet Social Responsability Management Systems SR-10; e a Norma ABNT NBR 16001. Todas elas, proporcionam, junto à organização, auxílios para o gerenciamento de questões de alta complexidade, objetivando que estas possam atingir suas metas, como o desenvolvimento da sustentabilidade. Diante do exposto, bem como do conhecimento das normas e o que elas representam, pode-se compreender que as normas que envolvem a gestão da responsabilidade social contribuem efetivamente para a melhoria da vida no trabalho, devido sua estruturação e formas de abordagem (ANDRADE et al., 2018).

O estudo de Mascarenhas et al. (2019) intitulado: Gestão de recursos humanos sustentável e responsabilidade socioambiental: uma agenda para debates, apontam que a gestão de pessoas também 
passa por essa interface de recursos renováveis principalmente com o surgimento da quarta revolução industrial, as organizações estão em mudanças sustentáveis não só no território ao redor das organizações mas sim no quadro de operações internas, potencializando o crescimento organizacional e melhorando a qualidade de vida. Essa perspectiva liga relações entre o trabalho e o meio ambiente. $O$ meio ambiente disponibilizando recursos naturais, químico e físico já o trabalho é uma visão estratégica onde ver o mercado como um todo, fraquezas, ameaças e que habilidades serão necessárias para se manter.

$\mathrm{O}$ RH passa por uma vertente na busca de melhorar seus princípios éticos dentro das organizações e como irá refletir no desenvolvimento do colaborador nas suas atividades administrativas e como é decisivo na produção de discursos na organização. Esse novo conceito procura proporcionar uma aproximação de colaboradores para o desenvolvimento de decisões gerenciais buscando aumentar os status organizacional e também o impacto negativo ao sujeito. E como isso irá bloquear o comportamento do indivíduo impedindo sua contribuição no meio organizacional. Por falta de reconhecimento do indivíduo ter dificuldade com a comunicação dos departamentos e assim dificultando a sua integração (MASCARENHAS et al., 2019).

A Responsabilidade Social Empresarial também abrange as questões de gênero, assim Proni et al. (2018) no estudo, Discriminação de gênero em grandes empresas no Brasil, destacam que é notório que desde os primórdios as mulheres sofrem discriminação em relação ao seu meio de trabalho, certo que o país já evoluiu consideravelmente, levando em conta que hoje a mulher, já consegue votar, tem direito a escola, podendo até ocupar um alto cargo em uma empresa, entretanto, o Brasil ainda tem muito o que melhorar, ainda que as mulheres sejam hoje em média mais escolarizadas do que os homens, nossa desigualdade de renda e desemprego entre homens e mulheres ainda é impressionantemente expressiva na maioria dos Estados. O IBGE, publicou uma pesquisa em 2018 que indicava a queda das mulheres em cargos de gestão dentro de um período de 4 anos. Em 2019, por sua vez, uma pesquisa da Folha já indicou uma leve melhora neste cenário, possivelmente graças à visibilidade que o tema tem recebido na mídia. Mas como podemos ajudar?. Primeiramente a conscientização deve começar por nós mesmos, um conselho é investir em bons líderes para a sua empresa, independente do gênero, que sejam pessoas que possuem boas ideias, que estes reconheçam o trabalho da mulher, que traga consigo maneiras de inclusão, que ele possa reconhecer a mulher tal qual reconhece o do homem.

Vocês acham que estamos melhorando?. Embora exista a crença de que as mulheres já chegaram lá, elas ainda são minoria no comando das empresas. Segundo dados divulgados pelo Instituto Brasileiro de Geografia e Estatística (IBGE), o número de mulheres nos cargos gerenciais caiu de quase $40 \%$ para $38 \%$, em quatro anos. Pesquisas mostram que metade dos homens acreditam que as mulheres estão, sim, representadas na liderança. Mas um estudo da consultoria McKinsey mostra que há apenas uma mulher em cargo de chefia para cada 10 homens, isso é um disparate, a sociedade não quer enxergar o óbvio, é fácil chegar e falar que uma mulher pode fazer o que ela quiser ou que ela pode ocupar um algo cargo em uma empresa, mas a realidade é completamente distorcida pelo patriarcado, a mulher vem lutando, dia a pois dia para conquistar um posto mais alto, para conquistar o seu lugar, e um simples homem estraga isso, considerar uma mulher inferior a um homem é uma atitude que não condiz com o atual contexto social, mas 
nas grandes empresas Brasileiras notamos isso (PRONI et al., 2018).

Se você está entrando no mercado de trabalho neste momento, é claro que ainda não está na posição de contribuir para grandes mudanças, porém é fundamental que você propague esta mentalidade igualitária. A discriminação de gênero no trabalho é ainda um dos grandes problemas a ser enfrentado pela nossa sociedade, mas está de tal forma enraizada que é necessária a conscientização de todos para caminharmos para uma realidade melhor no futuro (PRONI et al., 2018).

\section{CONCLUSÕES}

Na construção deste artigo podemos observar que a responsabilidade social vem se tornando dentro do mercado uma ferramenta para que as empresas conseguem se destacar dentro do contexto da sociedade promovendo assim um bem-estar para os mesmos. Toda via, as empresas ainda continuam buscando seus lucros, mas compreendendo que se há o desenvolvimento regional e local de modo sustentável, há uma maior chance de crescimento empresarial, uma vez que as mudanças nas realidades individuais e coletivas adentram nas organizações na forma de colaboradores mais motivados, com melhor saúde e educação.

As organizações que adotam a responsabilidade social acabam sendo bem vistas para as pessoas, promovendo o bem-estar e o lazer do mesmo, isso se torna um diferencial enorme entre outras empresas. Que esse estudo possa servir como fonte de pesquisa para outros estudos no futuro, e que seja mais refinada no futuro com a aplicabilidade de pesquisa de campo vendo como a importância da responsabilidade social implica no contexto organizacional.

\section{REFERÊNCIAS}

ANDRADE, V. F.; BIZZO, W. A.. Análise comparativa das normas de gestão de responsabilidade social e sua abrangência. Gest. Prod., São Carlos, v.25, n.4, 2018.

FLICK, U.. Desenho da pesquisa qualitativa. Porto Alegre: Artmed, 2009.

GIL, A. C.. Métodos e técnicas de pesquisa social. 6 ed. São Paulo: Atlas, 2009.

MARCONI, M. A.; LAKATOS, E. M.. Fundamentos de metodologia científica. 8 ed. São Paulo: Atlas, 2017.

MASCARENHAS, A. O.; BARBOSA, A. C. Q.. Gestão de recursos humanos sustentável e responsabilidade socioambiental: uma agenda para debates. RAE, São Paulo, v.59, n.5, 2019

PAIVA, F. C. S.; GIESTA, L. C.. Gestão socioambiental em micro e pequenas indústrias de Pau dos Ferros/RN. Gest.

Prod., São Carlos, v.26, n.2, 2019.
PRONI, T. T. R. W.; PRONI, M. W.. Discriminação de gênero em grandes empresas no Brasil. Revista Estudos Feministas, Florianópolis, v.26, n.1, 2018.

RABAÇA, A. C.; BARBOSA, G. G.. Dicionário de Comunicação. 2 ed. Rio de Janeiro: Campus, 2001.

REIS, C. N.. A responsabilidade social das empresas: o contexto brasileiro em face da ação consciente ou do modernismo do mercado?. Rev. Econ. Contemp., Rio de Janeiro, v.11, n.2, 2007.

RICO, E. M.. A responsabilidade social empresarial e o Estado: uma aliança para o desenvolvimento sustentável. São Paulo Perspec., São Paulo, v.18, n.4, 2004 .

SERPA, D. A. F.; FOURNEAU, L. F.. Responsabilidade social corporativa: uma investigação sobre a percepção do consumidor. Rev. Adm. Contemp., Curitiba, v.11, n.3, 2007.

SIMÕES, C. P.. Responsabilidade social e cidadania: conceitos e ferramentas. Brasília: SESI, 2008.

A CBPC - Companhia Brasileira de Produção Científica (CNPJ: 11.221.422/0001-03) detém os direitos materiais desta publicação. Os direitos referem-se à publicação do trabalho em qualquer parte do mundo, incluindo os direitos às renovações, expansões e disseminaç̃oses da contribuição, bem como outros direitos subsidiários. Todos os trabalhos publicados eletronicamente poderão posteriormente ser publicados em coletâneas impressas sob coordenação da Sustenere Publishing, da Companhia Brasileira de Produção Científica e seus parceiros autorizados. Os (as) autores (as) preservam os direitos autorais, mas não têm permissão para a publicação da contribuição em outro meio, impresso ou digital, em português ou em tradução. 